\title{
Article
}

\section{Osmotic heat engine using thermally responsive ionic liquids}

Yujiang Zhong, Xinbo Wang, Xiaoshuang Feng, Selvedin Telalovic,

Yves Gnanou, Kuo-Wei Huang, Xiao Matthew Hu, and Zhiping Lai

Environ. Sci. Technol., Just Accepted Manuscript • DOI: 10.1021/acs.est.7b02558 • Publication Date (Web): 11 Jul 2017

Downloaded from http://pubs.acs.org on July 17, 2017

\section{Just Accepted}

"Just Accepted" manuscripts have been peer-reviewed and accepted for publication. They are posted online prior to technical editing, formatting for publication and author proofing. The American Chemical Society provides "Just Accepted" as a free service to the research community to expedite the dissemination of scientific material as soon as possible after acceptance. "Just Accepted" manuscripts appear in full in PDF format accompanied by an HTML abstract. "Just Accepted" manuscripts have been fully peer reviewed, but should not be considered the official version of record. They are accessible to all readers and citable by the Digital Object Identifier (DOI®). "Just Accepted" is an optional service offered to authors. Therefore, the "Just Accepted" Web site may not include all articles that will be published in the journal. After a manuscript is technically edited and formatted, it will be removed from the "Just Accepted" Web site and published as an ASAP article. Note that technical editing may introduce minor changes to the manuscript text and/or graphics which could affect content, and all legal disclaimers and ethical guidelines that apply to the journal pertain. ACS cannot be held responsible for errors or consequences arising from the use of information contained in these "Just Accepted" manuscripts. 


\section{Osmotic heat engine using thermally responsive}

\section{ionic liquids}

3 Yujiang Zhong $^{a \dagger}$, Xinbo Wang $^{a \dagger}$, Xiaoshuang Feng ${ }^{a}$, Selvedin Telalovic ${ }^{a}$, Yves Gnanou ${ }^{a}$, Kuo-

4 Wei Huang ${ }^{a}$, Xiao Huc ${ }^{b c^{*}}$, Zhiping Lai ${ }^{a^{*}}$

$5{ }^{a}$ Division of Physical Science and Engineering, King Abdullah University of Science and

6 Technology, Thuwal, 23955-6900, Saudi Arabia.

$7 \quad{ }^{\mathrm{b}}$ School of Material Science and Engineering, Nanyang Technological University, Singapore.

$8{ }^{\mathrm{c}}$ Environmental Chemistry and Materials Centre, Nanyang Environment and Water Research

9 Institute.

10 These authors contribute equally.

11 ABSTRACT: The osmotic heat engine (OHE) is a promising technology for converting low

12 grade heat to electricity. Most of the existing studies have focused on thermolytic salt systems.

13 Herein, for the first time, we proposed to use thermally responsive ionic liquids (TRIL) that have

14 either an upper critical solution temperature (UCST) or lower critical solution temperature

15 (LCST) type of phase behavior as novel thermolytic osmotic agents. Closed-loop TRIL-OHEs

16 were designed based on these unique phase behaviors to convert low grade heat to work or

17 electricity. Experimental studies using two UCST-type TRILs, protonated betaine

18 bis(trifluoromethyl sulfonyl)imide $\left([\mathrm{Hbet}]\left[\mathrm{Tf}_{2} \mathrm{~N}\right]\right)$ and choline bis(trifluoromethylsulfonyl)imide

19 ([Choline][Tf $2 \mathrm{~N}])$ showed that (1) the specific energy of the TRIL-OHE system could reach as 
20 high as 4.0 times that of the seawater and river water system, (2) the power density measured

21 from a commercial FO membrane reached up to $2.3 \mathrm{~W} / \mathrm{m}^{2}$, and (3) the overall energy efficiency

22 reached up to $2.6 \%$ or $18 \%$ of the Carnot efficiency at no heat recovery and up to $10.5 \%$ or $71 \%$

23 of the Carnet efficiency at 70\% heat recovery. All of these results clearly demonstrated the great

24 potential of using TRILs as novel osmotic agents to design high efficient OHEs for recovery of

25 low grade thermal energy to work or electricity.

26 TOC ART

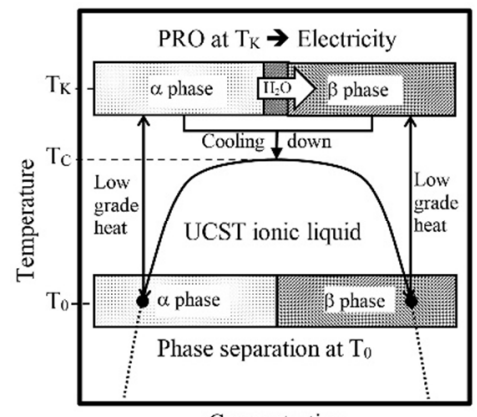

28 KEYWORDS: Osmotic heat engine, thermally responsive ionic liquid, low grade heat, pressure-

29 retarded osmosis, osmotic pressure

\section{INTRODUCTION}

31 Low grade heat with a temperature below $120^{\circ} \mathrm{C}$ is available in abundance not only from various

32 industrial processes but also from solar heating, geothermal energy, nuclear power and so on. It

33 is estimated that more than $50 \%$ of the energy in industry eventually ends up as low grade heat

34 due to process inefficiency. ${ }^{1,2}$ The concept of using OHE to recover low grade heat was first

35 proposed by Loeb in 1975 based on a pressure-retarded osmosis (PRO) process that uses a

36 semipermeable membrane to harvest the salinity gradient energy (SGE) and then uses low grade

37 heat to regenerate the salinity gradient. ${ }^{3}$ Compared with other technologies that are currently

38 under development such as the Rankine cycle, Sterling engines and solid-state devices based on 
39 the Seebeck effect, and so on, OHE is easy scalability, requires no addition of chemicals, and 40 produces zero discharge. ${ }^{1,4}$

41 The osmotic agent is the working medium of OHE. The first proposed osmotic agent is simply a 42 sodium chloride solution. Due to a small change in the boiling point of $\mathrm{NaCl}$ solution with 43 concentration, this approach is limited by its low efficiency. ${ }^{5}$ Hence, most OHE studies have

44 focused on thermolytic salt systems for which solubility changes dramatically with temperature. ${ }^{6}$

45 The most famous example is probably the $\mathrm{NH}_{3}-\mathrm{CO}_{2}$ system developed by Elimelech et al. By 46 using a conventional steam stripping system to regenerate the solution, the overall efficiency was 47 improved to around $1 \% .^{7}$ A broader range of $\mathrm{OHE}$ devices include also electrochemical 48 concentration cells and capacitive mixing or mixing entropy batteries. ${ }^{8-16}$ Ammonia has a low

49 molecular weight, which on the one hand offers the advantage of high solubility and therefore a 50 high power density, whereas on the other hand it causes a high membrane cross-over rate which 51 reduces the efficiency. Furthermore, its toxicity and unpleasant odor make it difficult to handle.

52 Hence, developing a good osmotic agent is still a large challenge in OHE development.

53 Herein, we propose a novel idea of using thermally responsive ionic liquids (TRILs) as the 54 osmotic agent. Ionic liquids (ILs) are electrolytes with a melting point typically lower than room 55 temperature. ${ }^{17}$ They are often considered as green solvents and have found broad applications in 56 catalysis, separation, food and pharmaceutical processes, and so on. ${ }^{17,18}$ Thermally responsive 57 ionic liquids have phase diagrams with either an upper critical solution temperature (UCST) or a 58 lower critical solution temperature (LCST). In our previous reports we demonstrated that both 59 UCST- and LCST-types of ILs can be used as novel draw solutions in the forward osmosis 60 processes for water desalination. ${ }^{19,20}$ As an osmotic agent, ILs have a number of advantages. ILs 61 are electrolytes that can dissociate into ions and generate higher osmotic pressure. ILs are 
62 typically large molecules, which minimize the crossover issue. ILs are liquids. The phase

63 separation is much faster than other thermally responsive agents such as polymers, and it will not

64 cause membrane fouling or flow blocking. ${ }^{21}$ ILs have high boiling points and low vapor

65 pressures, reducing the potential material loss during heating/cooling cycles. Hence, TRILs are

66 expected to be a very promising type of osmotic agent. The disadvantages of ILs are high cost,

67 high viscosity, and low diffusion coefficient that may leads to large concentration polarization.

68 The specific energy (SE) and power density (PD) are two figure-of-merit parameters for an

69 OHE. The specific energy is determined by the Gibbs energy of mixing, which is determined by

70 the maximum osmotic pressure difference. Power density is a property primarily related to

71 membrane performance, but it is also related to the maximum osmotic pressure difference

72 because from process design studies it was found that the maximum power density occurs

73 typically at the condition when the retarded pressure is equal to half of the maximum osmotic

74 pressure difference. ${ }^{22}$ Hence, the maximum osmotic pressure difference is a critical value.

75 Herein, we use two UCST-type ILs, protonated betaine bis(trifluoromethylsulfonyl)imide

$76\left([\mathrm{Hbet}]\left[\mathrm{Tf}_{2} \mathrm{~N}\right]\right)$ and choline bis(trifluoromethylsulfonyl)imide ([Choline $\left.]\left[\mathrm{Tf}_{2} \mathrm{~N}\right]\right)$, to illustrate the

77 OHE concept and to demonstrate the potential performance from osmotic pressure 78 measurements.

\section{MATERIALS AND METHODS}

80 Materials. $[$ Hbet $]\left[\mathrm{Tf}_{2} \mathrm{~N}\right](>99 \%)$ and $[$ Choline $]\left[\mathrm{Tf}_{2} \mathrm{~N}\right](>99 \%)$ were purchased from Shanghai

81 Chengjie Chemical Co., Ltd. Sodium chloride (>99.5\%) was purchased from Sigma-Aldrich. All

82 chemicals were used as received without further purification. Water purified by a Milli-Q (Milli

83 Pore) system was used as fresh water in all experiments. 
84 Measurements. The primary method to measure the concentration of IL and $\mathrm{NaCl}$ solutions is

85 through conductivity (Thermo Scientific ${ }^{\mathrm{TM}}$ Orion ${ }^{\mathrm{TM}} 5$ STAR and Orion ${ }^{\mathrm{TM}}$ 013005MD

86 Conductivity Cell). The solution needs to be diluted to low down the concentration to the linear

87 response region. For mixtures containing both $\mathrm{IL}$ and $\mathrm{NaCl}$, the conductivity measurement gives

88 the total ionic concentration. In this case the concentration of $\mathrm{NaCl}$ is determined through

89 measurement of chloride by an Aquakem 250 photometric analyzer (Thermo Scientific). The

90 concentration of IL was also verified by two methods: (1) UV-vis spectra (Cary 5000) if it is UV

91 sensitive, and (2) for the $\beta$ phase (IL-rich phase), the water content was measured by a standard

92 Karl Fischer Titrator (Mettler Toledo, C30X). The heat capacity of IL solution was detected by a

93 differential scanning calorimetry (Mettler Toledo DSC 1). The heat of mixing was measured by a

94 C80 calorimeter (Setaram). The solution density was determined from weight and volume

95 measurements. The osmotic pressure was measured by a custom-designed forward osmosis setup

96 as shown in Fig. 1. The setup contains two glass chambers, one filled with IL solution and the

97 other with $\mathrm{NaCl}$ solution. A polyamide reverse osmosis membrane (Toray, UTC-73AC), which

98 has a good salt rejection rate, was placed in the middle of the two chambers. The whole setup

99 was maintained at the working temperature $\mathrm{T}_{\mathrm{K}}$ by immersion in a water bath. An equivalent

$100 \mathrm{NaCl}$ solution having the same osmotic pressure as the IL solution was found by adjusting the

101 concentration of the $\mathrm{NaCl}$ solution until water transport through the membrane in both ways was

102 observed. The concentrations of $\mathrm{NaCl}$ and IL in both solutions were measured after the

103 experiment to ensure that the leakage rate across the membrane was negligible. 


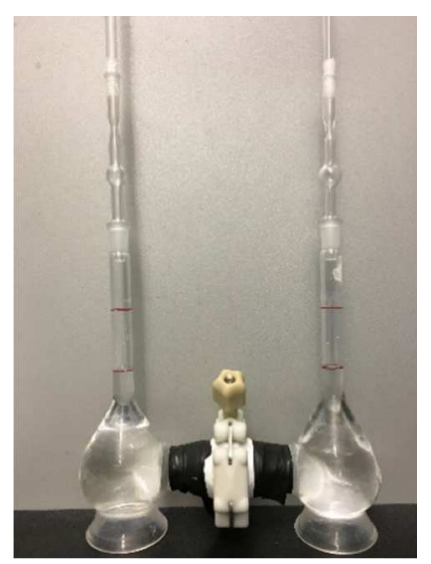

Figure 1. A custom-designed apparatus for osmotic pressure measurement.

\section{RESULTS AND DISCUSSION}

107 Fig. 2a shows the phase diagrams of the two ILs. Both phase diagrams exhibit a critical 108 temperature $\mathrm{T}_{\mathrm{c}}$, above which the IL is completely miscible with water but under which the 109 mixture separates spontaneously into a water-rich phase (denoted as $\alpha$ phase) and an ionic 110 liquid-rich phase (denoted as $\beta$ phase).
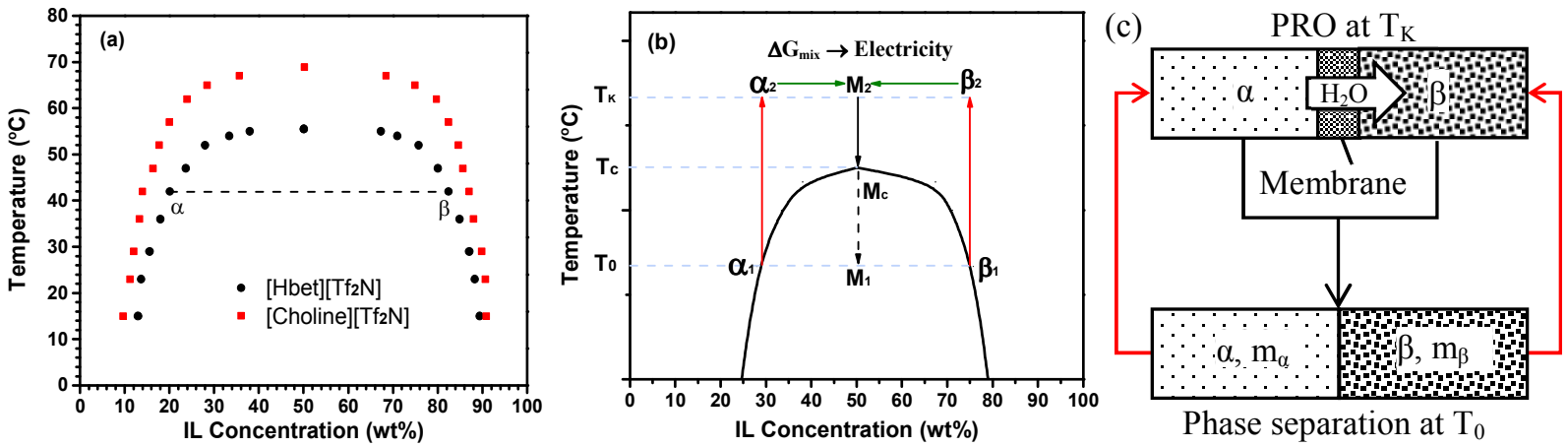

112 Figure 2. (a) Phase diagrams of $[\mathrm{Hbet}]\left[\mathrm{Tf}_{2} \mathrm{~N}\right]$ and $[$ Choline $]\left[\mathrm{Tf}_{2} \mathrm{~N}\right]$ aqueous solutions; (b)

113 Illustration of an TRIL-OHE loop on the phase diagram; (c) illustration of an TRIL-OHE by a 114 PRO process.

115 Based on the UCST phase behavior, a novel closed-loop TRIL-OHE was designed as illustrated 116 in Fig. 2b and Fig. 2c. The most studied pressure-retarded osmosis (PRO) process was used to 
117 demonstrate the energy conversion process in Fig. 2c, but other commonly studied processes

118 such as reverse electro dialysis (RED) and capacitance mixing (CM) can also be used. All of

119 these processes have $100 \%$ ideal efficiency if conducted reversibly ${ }^{4,11,23}$. The TRIL-OHE loop

120 includes three stages. The first stage starts from a temperature $\mathrm{T}_{0}$ (for example, room temperature

$12123^{\circ} \mathrm{C}$ ) which should be lower than the critical temperature $\mathrm{T}_{\mathrm{c}}$. The equilibrium pair of $\alpha$ and $\beta$

122 solutions obtained at $\mathrm{T}_{0}$ are heated separately to a working temperature $\mathrm{T}_{\mathrm{K}}$ that should be above

123 the critical temperature and then placed in the two sides of a semipermeable membrane which

124 allows the transport of water only. The second stage is the PRO process that is conducted 125 reversibly at $\mathrm{T}_{\mathrm{K}}$ by applying a pressure equal to the osmotic pressure difference of the two 126 solutions to the $\beta$ phase. Water is drawn from the $\alpha$ phase to the $\beta$ phase by osmotic pressure 127 which increases the volume of the $\beta$ phase and in turn generates either mechanical work or 128 electricity. Because $T_{K}$ is above the critical temperature, a single phase will eventually form after 129 mixing. The mixture is then cooled in the third stage to the initial temperature $\mathrm{T}_{0}$, regenerating 130 the original two phases. Table 1 lists all the operation parameters of the TRIL-OHE loop 131 assuming to generate $1000 \mathrm{~kg}$ mixture after the PRO process.

132 Table 1. Operation conditions of the TRIL-OHE loop for the two IL systems

\begin{tabular}{|c|c|c|c|c|c|c|c|c|c|}
\hline $\mathrm{IL}$ & $\begin{array}{c}\mathrm{Tc} \\
\left({ }^{\circ} \mathrm{C}\right)\end{array}$ & $\begin{array}{c}\mathrm{Wc} \\
(\mathrm{wt} \%)\end{array}$ & $\begin{array}{c}\mu \\
(\mathrm{Pa} \cdot \mathrm{s})\end{array}$ & $\begin{array}{c}\mathrm{T}_{0} \\
\left({ }^{\circ} \mathrm{C}\right)\end{array}$ & $\begin{array}{c}\mathrm{W} \alpha \\
(\mathrm{wt} \%)\end{array}$ & $\begin{array}{c}\mathrm{W}_{\beta} \\
(\mathrm{wt} \%)\end{array}$ & $\begin{array}{c}\mathrm{m}_{\alpha} \\
(\mathrm{kg})\end{array}$ & $\begin{array}{c}\mathrm{m}_{\beta} \\
(\mathrm{kg})\end{array}$ & $\begin{array}{c}\mathrm{T}_{\mathrm{K}} \\
\left({ }^{\circ} \mathrm{C}\right)\end{array}$ \\
\hline$[$ Hbet $]\left[\mathrm{Tf}_{2} \mathrm{~N}\right]$ & 55.6 & 50.1 & 0.030 & 23.0 & 13.7 & 88.3 & 512.06 & 487.94 & 60.0 \\
\hline$[$ Choline $]\left[\mathrm{Tf}_{2} \mathrm{~N}\right]$ & 68.9 & 50.2 & 0.024 & 23.0 & 11.2 & 90.7 & 509.43 & 490.57 & 74.0 \\
\hline
\end{tabular}

$133 \mathrm{~T}_{\mathrm{C}}$, critical temperature; $\mathrm{W}_{\mathrm{C}}$, critical concentration; $\mu$, viscosity measured at $\mathrm{T}_{\mathrm{K}} ; \mathrm{T}_{0}$, initial 134 temperature; $\mathrm{W}_{\alpha}$, concentration of $\alpha$ phase at $\mathrm{T}_{0} ; \mathrm{W}_{\beta}$, concentration of $\beta$ phase at $\mathrm{T}_{0} ; \mathrm{m}_{\alpha}$, amount 135 of $\alpha$ phase; $\mathrm{m}_{\beta}$, amount of $\beta$ phase; $\mathrm{T}_{\mathrm{K}}$, working temperature.

137 The maximum energy that can be extracted out of SGE is the Gibbs mixing energy, which in 138 principle can be calculated from thermodynamic models. ${ }^{24-26}$ Most of these models, however, 
139 contain empirical parameters which are not available due to the limit of experimental data.

140 Hence, herein the Gibbs mixing energy was obtained through experimental measurement of the

141 osmotic pressure based on the following equation:

$$
\Delta G_{m i x}=-\int_{0}^{V} \Delta \pi d V
$$

143 where $\Delta \pi$ is the osmotic pressure difference between the $\alpha$ and $\beta$ phases, and $\mathrm{V}$ is the total

144 amount of water drawn from the $\alpha$ to $\beta$ phase during the PRO process. Unfortunately, the 145 osmotic pressure of TRILs cannot be measured by commercial osmometers because they 146 typically utilize colligative properties such as the decrease in melting point. Therefore, a custom147 designed forward osmosis (FO) setup was built as shown in Fig. 1.

148 The mechanism of measurement was to use the sodium chloride solution as a reference to find

149 the equivalent osmotic pressure of the ionic liquid solution by observing the transport of water in 150 a trial-and-error fashion. If the osmotic pressures of the two solutions are equal, then no water 151 should pass through the membrane. Otherwise water will be extracted from the solution with a 152 lower osmotic pressure to the solution with the higher one. During the experiment, one container 153 was filled with sodium chloride solution with a known concentration while the other was filled 154 with an ionic liquid solution with a known concentration. The whole setup was immerged into a 155 circulation bath to maintain the temperature at the working temperature $T_{K}$, which was selected 156 as approximately $5{ }^{\circ} \mathrm{C}$ above the critical temperature in this study. The osmotic pressures of the $157 \mathrm{NaCl}$ solution at different salt concentrations are available from a reference ${ }^{27}$ and shown in Fig. $1583 a$.

159 Table 2 shows an example of how the equivalent osmotic pressure of a $1.14 \mathrm{M}(40 \mathrm{wt} \%)$ $160[$ Hbet $]\left[\mathrm{Tf}_{2} \mathrm{~N}\right]$ solution was determined at $\mathrm{T}_{\mathrm{K}}=60^{\circ} \mathrm{C}$. A $1.035 \mathrm{M} \mathrm{NaCl}$ solution was first tested. 
161 After 22 hours, it was found that $0.792 \mathrm{~g}$ of water was extracted from the ionic liquid to the $\mathrm{NaCl}$

162 solution, indicating that the equivalent osmotic pressure of the ionic liquid solution should be

163 lower. Hence, the concentration of the $\mathrm{NaCl}$ solution was lowered to $1.0 \mathrm{M}$, then to $0.937 \mathrm{M}$, and

164 finally to $0.92 \mathrm{M}$. The amount of water extracted from the ionic liquid to $\mathrm{NaCl}$ became

165 increasingly lower until a reverse transport of water was observed at the last measurement. The

166 average value of the last two measurements was used as the final result. The error of

167 measurement of this approach is estimated to be less than $1 \%$. Table 2 also showed the total

168 conductivity $(\kappa)$ of the solutions before and after each trial, and the conductivity in parenthesis

169 showed the contribution from the minor component, i.e. $\mathrm{NaCl}$ in IL solution or IL in $\mathrm{NaCl}$

170 solution. As the data shown, the changes in total conductivities before and after each trial

171 matched very well with the direction of water transport, verifying the accuracy of our

172 measurements. For example, when water was extracted from IL solution to $\mathrm{NaCl}$ solution, the

173 conductivity of IL solution increased while that of $\mathrm{NaCl}$ solution decreased, or vice versa. The

174 minor component is due to leakage during experiment. Their conductivities were less than $0.5 \%$

175 of the total conductivity, indicating that the leakage rate was very small. Based on the FO

176 measurements, the equivalent osmotic pressure of the two ILs at different IL concentrations are

177 shown in Fig. 3b.

178 Table 2. Osmotic pressure detection for a $1.14 \mathrm{M}(40 \mathrm{wt} \%)[\mathrm{Hbet}][\mathrm{Tf} 2 \mathrm{~N}]$ water solution at $60{ }^{\circ} \mathrm{C}$

\begin{tabular}{|c|c|c|c|c|c|c|c|c|c|c|}
\hline \multirow[b]{2}{*}{ Trial } & \multirow{2}{*}{$\begin{array}{c}\text { IL } \\
\text { Conc. } \\
\text { (M) }\end{array}$} & \multirow{2}{*}{$\begin{array}{c}\mathrm{NaCl} \\
\text { Conc. } \\
(\mathrm{M})\end{array}$} & \multirow[b]{2}{*}{$\begin{array}{l}\text { Time } \\
\text { (h) }\end{array}$} & \multirow{2}{*}{$\begin{array}{c}\text { Water } \\
\text { Pass } \\
(\mathrm{h})\end{array}$} & \multirow{2}{*}{$\begin{array}{c}\text { Water } \\
\text { Flux } \\
(\mathrm{LMH})\end{array}$} & \multicolumn{2}{|c|}{ IL side (dilute 5 times) } & \multicolumn{3}{|c|}{$\mathrm{NaCl}$ side (dilute100 times) } \\
\hline & & & & & & $\begin{array}{c}\kappa \_ \text {before } \\
(\overline{\mathrm{ms}} / \mathrm{cm})\end{array}$ & $\begin{array}{c}\text { א_after } \\
(\mathrm{ms} / \mathrm{cm})\end{array}$ & $\begin{array}{c}\kappa \_ \text {before } \\
(\mu \mathrm{s} / \mathrm{cm})\end{array}$ & & \\
\hline 1 & 1.14 & 1.035 & 22 & 0.792 & 0.0 & & $.27(0$ & 1322 & & \\
\hline 2 & 1.14 & 00 & 27 & 0.509 & 0.0 & & $94(0$. & 1196 & & \\
\hline 3 & 1.14 & 37 & 21 & 0.057 & 0.006 & 20 & $12(0 .($ & 1013 & 1005 & (1. \\
\hline 4 & 1.14 & .920 & 20 & -0.055 & -0.006 & 20.06 & $19.98(0.042)$ & 965 & $9^{\prime}$ & $(1.15)$ \\
\hline
\end{tabular}



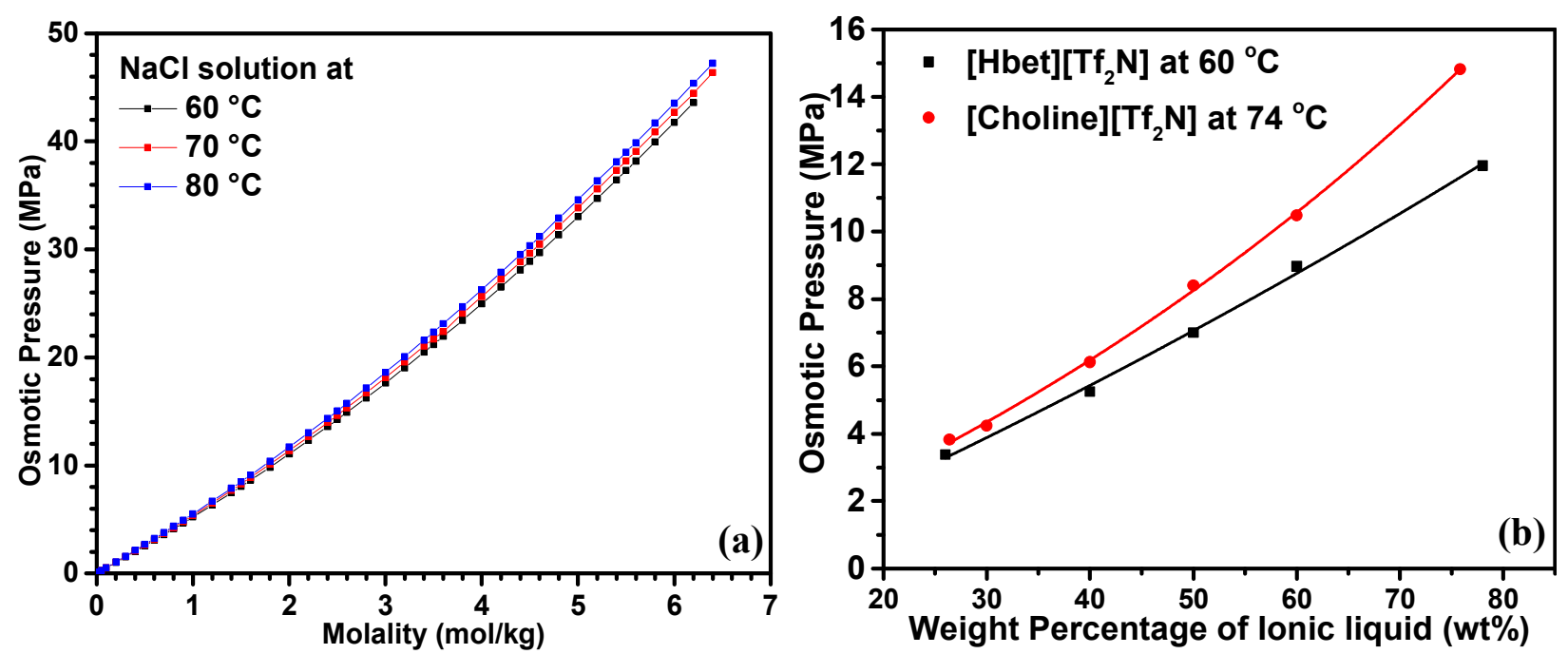

Figure 3. (a) Osmotic pressure of $\mathrm{NaCl}$ aqueous solution at different molality and temperature.

182 Data obtained from a reference; ${ }^{27}$ (b) osmotic pressures of the two IL solutions at different

183 weight percentage measured at $\mathrm{T}_{\mathrm{K}}$.

184 The Gibbs mixing energy can then be calculated as follows. Assuming $f(x)$ is the function of the 185 equivalent osmotic pressure at weight percentage $x$, which can be data fitted from Fig. 3b, and V 186 is the amount of water extracted from the $\alpha$ phase to the $\beta$ phase, then the osmotic pressure 187 difference of the two phases $\Delta \pi$ can be calculated from the following equation:

$$
\Delta \pi=f\left(\frac{m_{\beta} W_{\beta}}{m_{\beta}+\rho V}\right)-f\left(\frac{m_{\alpha} W_{\alpha}}{m_{\alpha}-\rho V}\right)
$$

189 where $m_{\alpha}, W_{\alpha}, m_{\beta}$, and $W_{\beta}$ are the amount and the weight percentage of the $\alpha$ and $\beta$ phases,

190 respectively, and $\rho$ is the density of pure water. The total amount of ionic liquid $\mathrm{m}_{\alpha}+\mathrm{m}_{\beta}$ was

191 fixed at $1000 \mathrm{~kg}$. The concentrations of the $\alpha$ and $\beta$ phases were determined by the initial

192 temperature $\mathrm{T}_{0}$. It was further assumed that after mixing the mixture had the same concentration

193 as the critical concentration. Then $\mathrm{m}_{\alpha}$ and $\mathrm{m}_{\beta}$ in Equation (2) can be calculated accordingly. Fig.

194 4a shows the relationship of $\Delta \pi$ vs. $\mathrm{V}$ of the two ionic liquid systems when the initial 195 temperature was fixed at room temperature $\left(23^{\circ} \mathrm{C}\right)$. The areas under the curves are the maximum 10 
196 Gibbs mixing energy per $1000 \mathrm{~kg}$ of the total mixed ionic liquid solutions, or the specific energy,

197 SE, of the system. Fig. $4 \mathrm{~b}$ shows the specific energies at different initial temperatures.

198 Obviously, the lower the initial temperature, the higher is the concentration difference between

199 the $\alpha$ and $\beta$ phases and thus the higher the specific energy. At $23^{\circ} \mathrm{C}$, the specific energy was

200 approximately $2500 \mathrm{~kJ} / \mathrm{t}$ for $\left[\mathrm{Hbet}_{[}\left[\mathrm{Tf}_{2} \mathrm{~N}\right]\right.$ and $3700 \mathrm{~kJ} / \mathrm{t}$ for [Choline][Tf $\left.2 \mathrm{~N}\right]$. It is worthy to note

201 that the specific energy between regular seawater and river water was approximately $912 \mathrm{~kJ} / \mathrm{t}^{28}$

202 Thus, the specific energy of the two ionic liquids are approximately 1.74 and 3.06 times higher.

203 The specific energy can be further optimized in terms of the mass ratio of two phases. Fig. 4c

204 shows the specific energy at different $m_{\beta} /\left(m_{\alpha}+m_{\beta}\right)$. The optimal ratio was found to be 1.157 for

$205[$ Hbet $]\left[\mathrm{Tf}_{2} \mathrm{~N}\right]$ and 1.075 for $[$ Choline $]\left[\mathrm{Tf}_{2} \mathrm{~N}\right]$. Interestingly, these ratios were exactly the same

206 values after mixing when the concentration of the mixture was equal to the critical concentration.
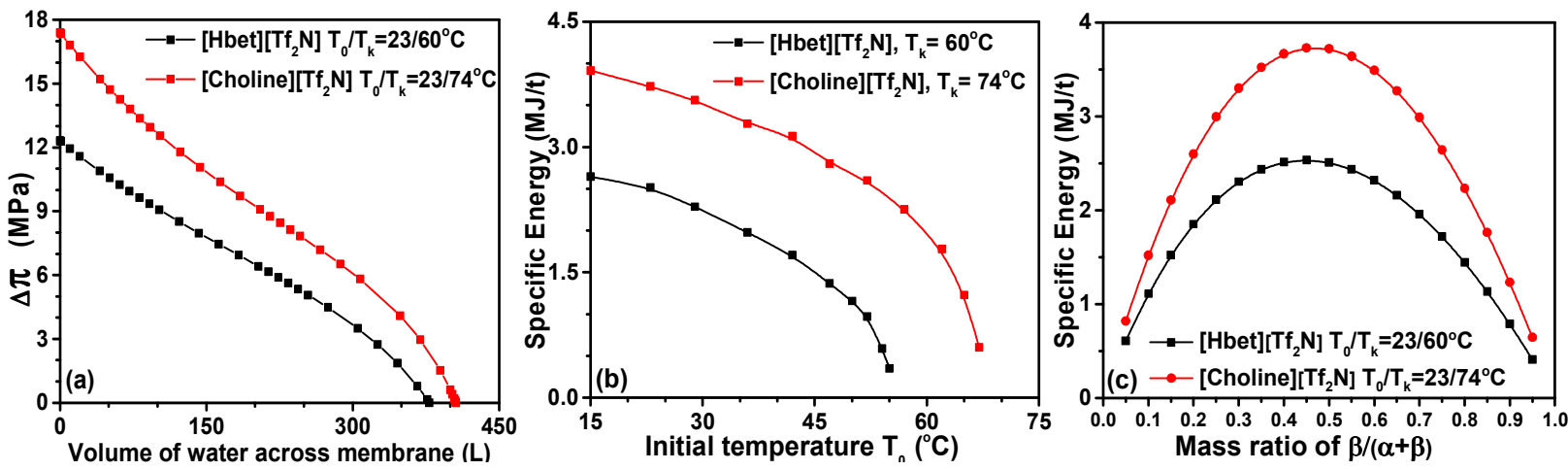

208 Figure 4. (a) Osmotic pressure difference at different amounts of water drawn across the

209 membrane from the $\alpha$ to $\beta$ phase at the working temperature $\mathrm{T}_{\mathrm{K}}$, (b) specific energy at different

210 initial temperature $T_{0}$, and (c) the specific energy at different $m_{\beta} /\left(m_{\alpha}+m_{\beta}\right)$ ratios from the room

211 temperature $\alpha / \beta$ pair. 
212 Power density (PD) is a measure of the energy generated per unit time and unit membrane area.

213 It is an important performance index of the PRO process. The gross power density can be 214 calculated as the product of water flux $J_{w}$ and the hydraulic pressure difference $\Delta P$.

$215 \quad P D=J_{w} \Delta P$

216 In the ideal case,

$217 \quad P D=A(\Delta \pi-\Delta P) \Delta P$

218 It reaches the maximum when $\Delta P=\pi_{\max } / 2^{22}$ and thus,

$$
\mathrm{PD}_{\max }=\frac{1}{4} A \Delta \pi_{\max }^{2}
$$

220 The maximum osmotic pressure difference $\Delta \pi_{\max }$ in Equation (5) can be read directly from Fig.

$2214 a$, but the water permeability coefficient, A, is a membrane property. From the osmotic pressure

222 measurements, it was found that the commercial HTIC membrane, which is made from cellulose

223 acetate and often used for FO or PRO processes, was not stable in the ionic liquid. Hence, during

224 the osmotic pressure measurement a commercial polyamide membrane (Toray, UTC-73AC) that

225 is typically used for reverse osmosis was used as the semipermeable membrane. The membrane

226 was found to be very stable even after hundreds of hours of testing. It has a good salt rejection

227 rate, which is beneficial for our fundamental studies to obtain the maximum Gibbs mixing

228 energy. However, the disadvantage of this membrane is its low water flux which will lead to low

229 power density. Another commercial FO membrane HTI OsMem ${ }^{\mathrm{TM}}$ TFC-ES Membrane was

230 found stable and gave relatively higher water flux. The measured water flux between the $\alpha$ and $\beta$

231 phases were $1.71 \mathrm{LMH}$ for $[\mathrm{Hbet}]\left[\mathrm{Tf}_{2} \mathrm{~N}\right]$ at $60{ }^{\circ} \mathrm{C}$ and $1.95 \mathrm{LMH}$ for $[$ Choline $]\left[\mathrm{Tf}_{2} \mathrm{~N}\right]$ at $74{ }^{\circ} \mathrm{C}$.

232 Using the ideal equation (4) the A values were calculated to be $0.014 \mathrm{LMH} / \mathrm{bar}$ for $[\mathrm{Hbet}]\left[\mathrm{Tf}_{2} \mathrm{~N}\right]$

233 and $0.011 \mathrm{LMH} /$ bar for $[$ Choline $]\left[\mathrm{Tf}_{2} \mathrm{~N}\right]$. Correspondingly, the maximum power density

234 calculated from Equation (5) gives $1.5 \mathrm{~W} / \mathrm{m}^{2}$ for $[\mathrm{Hbet}]\left[\mathrm{Tf}_{2} \mathrm{~N}\right]$ and $2.3 \mathrm{~W} / \mathrm{m}^{2}$ for 12 
235 [Choline][Tf $2 \mathrm{~N}]$. These values are comparable to many reports for the seawater-river water 236 system. $^{29}, 30$ It should be noted that the A values were estimated without considering 237 concentration polarization, which is a well-known issue in FO and PRO processes that leads to 238 reduced driving force across the membrane. ${ }^{31}$ Hence, the intrinsic A values without centration 239 polarization should be larger and the corresponding power density should be higher. ${ }^{32}$ Recently, 240 a number of high-flux polyamide type of thin film composite (TFC) membranes have been 241 successfully developed for the PRO process with A value reached up to $1 \mathrm{LMH} / \mathrm{bar}^{33}$ Hence, 242 there should be a big room for further improvement of the power density for the TRIL-OHE 243 system in order to meet the economic requirements. ${ }^{34}$

244 The temperature vs. entropy of the TRIL-OHE cycle is shown in Fig. 5. In the first stage, the 245 system requires $Q_{\alpha}+Q_{\beta}$ amount of heat to increase the temperature from $\mathrm{T}_{0}$ to $\mathrm{T}_{\mathrm{K}}$. The entropy 246 of the system will increase with temperature roughly by amount of $\left(C_{P}^{\alpha}+C_{P}^{\beta}\right) \ln \frac{T_{K}}{T_{0}}$. In the 247 second stage, the PRO process operates isothermally, thus temperature will keep constant, but 248 since it is a spontaneous mixing process, so entropy will increase by amount of $\Delta S_{\text {mix }}$. The 249 system in this stage may adsorb or release heat depending on the heat of mixing $\Delta H_{\text {mix }}$. In the 250 third step, the mixture is cooled down from $T_{K}$ to $T_{0}$, and the system recovers back to the original 251 state. The heat released from the third stage, $\mathrm{Q}_{\mathrm{m}}$, should be able to be recovered by a heat 252 exchanger coupling with the first stage. 


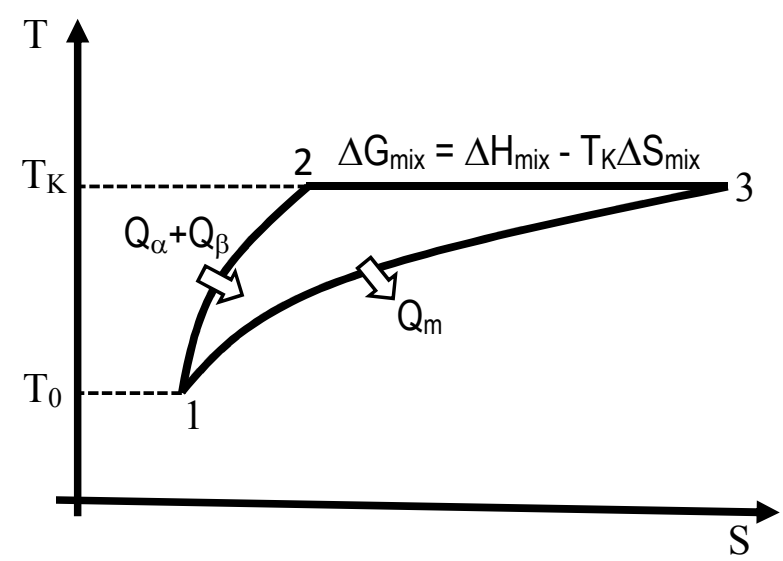

256 Based on the above T-S diagram, the energy balance of each step and the overall energy 257 efficiency can be calculated as below. The heat required for stage one is calculated by,

$258 \quad Q_{\alpha}+Q_{\beta}=m_{\alpha} \int_{T_{0}}^{T_{K}} C_{p}^{\alpha} d T+m_{\beta} \int_{T_{0}}^{T_{K}} C_{p}^{\beta} d T$

259 and the heat released in stage three is calculated by,

$$
Q_{m}=\left(m_{\alpha}+m_{\beta}\right) \int_{T_{0}}^{T_{K}} C_{p}^{m} d T
$$

261 where $C_{p}^{\alpha}, C_{p}^{\beta}$ and $C_{p}{ }^{m}$ are the heat capacities of the $\alpha$ phase, $\beta$ phase and mixture, respectively, 262 and their values at different temperatures are shown in Fig. 6a and 6b. It is noted that the mixture

263 will undergo phase separation during cooling. Hence, $\mathrm{C}_{\mathrm{p}}{ }^{\mathrm{m}}$ is the overall value of the two phases.

264 The energies involved in each step of the TRIL-OHE loop are listed in Table 3. 

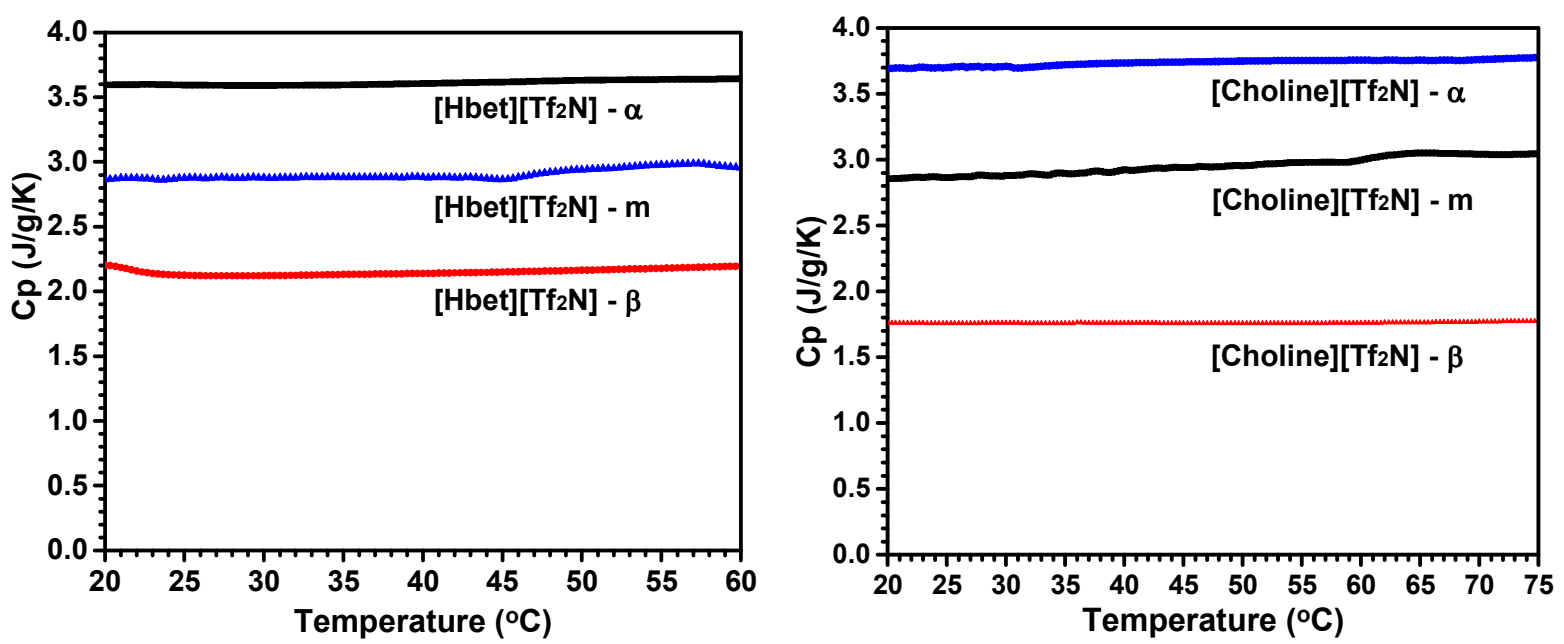

Figure 6. (a) Heat capacity of $[\mathrm{Hbet}]\left[\mathrm{Tf}_{2} \mathrm{~N}\right]$ in the process temperature range, (b) Heat capacity

267 of $[$ Choline $]\left[\mathrm{Tf}_{2} \mathrm{~N}\right]$ in the process temperature range.

268 Table 3. Energy at each step of the TRIL-OHE loop. All calculations are based on $1000 \mathrm{~kg}$ of 269 mixture and the operation conditions listed in Table 1.

\begin{tabular}{|l|l|l|l|l|}
\hline IL & $\Delta$ Gmix $(\mathrm{kJ})$ & $\Delta H_{\operatorname{mix}}(\mathrm{kJ})$ & $\mathrm{Q} \alpha+\mathrm{Q} \beta(\mathrm{kJ})$ & $\mathrm{Qm}(\mathrm{kJ})$ \\
\hline$[$ Hbet $]\left[\mathrm{Tf}_{2} \mathrm{~N}\right]$ & $-2.52 \times 10^{3}$ & 44 & $1.072 \times 10^{5}$ & $1.075 \times 10^{5}$ \\
\hline$[$ Choline $]\left[\mathrm{Tf}_{2} \mathrm{~N}\right]$ & $-3.73 \times 10^{3}$ & -190 & $1.412 \times 10^{5}$ & $1.507 \times 10^{5}$ \\
\hline
\end{tabular}

271 It is interesting to find $\left(m_{\alpha}+m_{\beta}\right) C_{P}^{m} \approx m_{\alpha} C_{P}^{\alpha}+m_{\beta} C_{P}^{\beta}$, and $Q_{m} \approx Q_{\alpha}+Q_{\beta}$. It implies that

272 the heat released from the third stage can be largely recovered through a heat exchanger coupling

273 with the first stage. Assuming the recovery rate is $\eta$, then the overall energy efficiency is,

$$
E=-\Delta G_{\text {mix }} /\left(Q_{\alpha}+Q_{\beta}-\eta Q_{2}+\Delta H_{\text {mix }}\right)
$$

275 Carnot efficiency is calculated by,

$$
E_{C}=\left(T_{K}-T_{0}\right) / T_{K}
$$

277 The Carnot efficiency for $[\mathrm{Hbet}]\left[\mathrm{Tf}_{2} \mathrm{~N}\right]$ system is around $11.1 \%$ and for [Choline $][\mathrm{Tf} 2 \mathrm{~N}]$ system

278 around $14.7 \%$. Fig. 7 shows the energy efficiency at different heat recovery rate. If assuming the 279 average temperature difference of the heat exchanger is about $10^{\circ} \mathrm{C}$, it is estimated that about 
$28070 \%$ heat of the $[$ Hbet $]\left[\mathrm{Tf}_{2} \mathrm{~N}\right]$ system and about $80 \%$ heat of the $\left[\right.$ Choline] $\left[\mathrm{Tf}_{2} \mathrm{~N}\right]$ system can be

281 recovered. As can be seen in Fig. 7, without heat recovery the energy efficiency is about $2.4 \%$

282 for $[\mathrm{Hbet}]\left[\mathrm{Tf}_{2} \mathrm{~N}\right]$ system and about $2.6 \%$ for $\left[\right.$ Choline] $\left[\mathrm{Tf}_{2} \mathrm{~N}\right]$ system, or $21 \%$ and $18 \%$ of their

283 Carnot efficiency, respectively. While at 70\% heat recovery, the efficiencies can reach as high as

$2847.9 \%$ and $10.5 \%$, or $71 \%$ and $71 \%$ of the Carnot efficiency for the two IL systems, respectively.

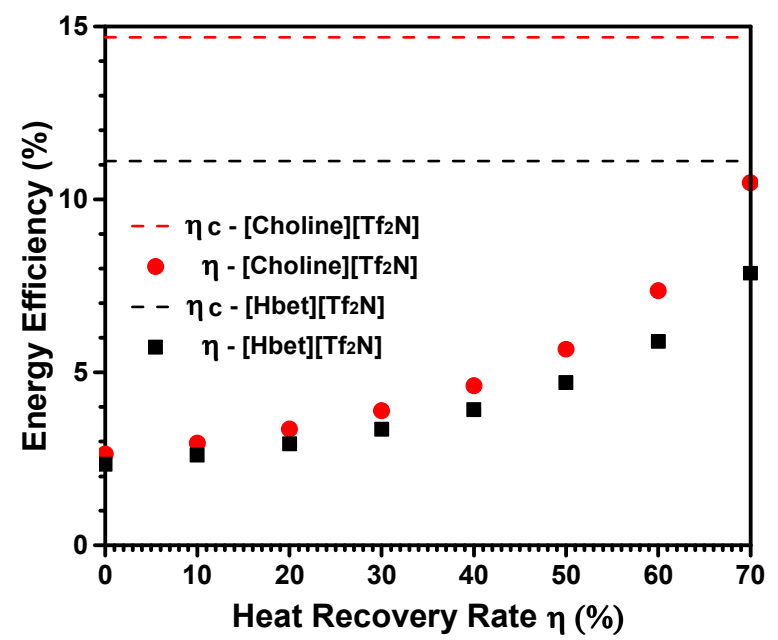

Figure 7. The energy efficiency at different heat recovery rate.

287 Based on the unique phase diagrams of two UCST type of ionic liquids, [Hbet][Tf $\mathrm{T}_{2} \mathrm{~N}$ and 288 [Choline] $\left[\mathrm{Tf}_{2} \mathrm{~N}\right]$, a novel closed-loop TRIL-OHE was designed to convert low grade thermal 289 energy to electricity. The osmotic pressures of the two ionic liquids were measured using a 290 custom-designed $\mathrm{FO}$ setup using $\mathrm{NaCl}$ solution as a reference. From the osmotic pressure data, 291 the specific energy and the power density, two performance metric parameters of OHE, were 292 estimated. The specific energy increases when the initial temperature decreases. When the initial 293 temperature is set at room temperature $\left(23^{\circ} \mathrm{C}\right)$, the specific energy of the $[\mathrm{Hbet}]\left[\mathrm{Tf}_{2} \mathrm{~N}\right]$ system 294 was around $2500 \mathrm{~kJ} / \mathrm{t}$ and that of the [Choline][Tf $\left.\mathrm{T}_{2} \mathrm{~N}\right]$ system around $3700 \mathrm{~kJ} / \mathrm{t}$, which are 2.7 and 2954.0 times the seawater and river water system, respectively. The maximum power density 296 measured from a commercial FO membrane is about $1.5 \mathrm{~W} / \mathrm{m}^{2}$ for the $\left.\left[\mathrm{Hbet}_{[}\right] \mathrm{Tf}_{2} \mathrm{~N}\right]$ system and 16 
$2972.3 \mathrm{~W} / \mathrm{m}^{2}$ for the $[$ Choline $]\left[\mathrm{Tf}_{2} \mathrm{~N}\right]$ system. The power density is obtained from a relatively low

298 permeable membrane. There should be still a big room to improve the power density if highly

299 permeable membranes are used. During the experiment, it was found that the cellulose acetate

300 type of membranes were not stable in ionic liquid solutions, but this was not an issue for

301 polyamide type of membranes. The temperature-entropy diagram of the TRIL-OHE loop was

302 analyzed. A notable advantage of the TRIL-OHE was revealed from the energy balance, that is,

303 the heat released from the cooling stage can be largely recovered. A rigorous energy balance

304 showed without heat recovery the energy efficiency was about $2.4 \%$ or $21 \%$ of the Carnot

305 efficiency for the $[\mathrm{Hbet}]\left[\mathrm{Tf}_{2} \mathrm{~N}\right]$ system, and about $2.6 \%$ or $18 \%$ of the Carnot efficiency for the

306 [Choline] $\left[\mathrm{Tf}_{2} \mathrm{~N}\right]$ system, while at $70 \%$ heat recovery, the energy efficiency increased to $7.9 \%$ or

$30771 \%$ of the Carnot efficiency and $10.5 \%$ or $71 \%$ of the Carnot efficiency for the two ionic liquid

308 systems, respectively. All of these results clearly demonstrated the superior performance of the

309 TRIL-OHE system. Therefore, this concept provided a very promising way to design efficient

310 OHEs for waste heat recovery.

\section{AUTHOR INFORMATION}

312 Corresponding Authors:

313 Prof. Xiao $\mathrm{Hu}$

314 Address: School of Materials Science \& Engineering, Nanyang Technological University. N4.1-

315 01-14, 50 Nanyang Avenue, Singapore 639798.

316 Phone: +6567904610

317 Fax: +65 67909081

318 Email: Asxhu@ntu.edu.sg

319 Prof. Zhiping Lai

320 Address: Al-Jazri Building (Building 4), Room 4218, 4700 King Abdullah University of Science 321 and Technology. Thuwal, 23955-6900, Kingdom of Saudi Arabia.

322 Phone: +966128082408

323 Fax: +966 128021328

324 Email: Zhiping.lai@kaust.edu.sa 


\section{AUTHOR CONTRIBUTIONS}

327 Y. Zhong and X. Wang did most of the experimental measurements and data analyses. S.

328 Telalovic contributed to the heat of capacity measurements. Z. Lai prepared the manuscript. Z.

329 Lai, and $\mathrm{X}$. Hu conceived the TRIL-OHE concept. X. Feng, K-W. Huang and Y. Gnanou

330 contributed to the design of the thermally responsive ILs.

\section{ACKNOWLEDGEMENTS}

332 The work was supported by KAUST competitive research grant URF/1/1723.

\section{ABBREVIATIONS}

$334 \alpha$ phase, water-rich phase; $\beta$ phase, ionic liquid -rich phase; $\mathrm{CM}$, capacitance mixing; FO,

335 forward osmosis; IL, Ionic liquids; TRIL, thermally responsive ionic liquid; LCST, lower critical

336 solution temperature; UCST, upper critical solution temperature; OHE, osmotic heat engine; PD,

337 power density; RED, reverse electro dialysis; SE, specific energy; SGE, salinity gradient energy;

338 Tc, critical temperature; $\mathrm{T}_{0}$, initial temperature; $\mathrm{T}_{\mathbf{K}}$, working temperature; $\mathrm{TFC}$, thin film

339 composite.

\section{REFERENCES}

341 1. BCS Incorporated, Waste heat recovery: technology and opportunities in US industry; 2008.

342 2. Alexander, S. R.; Srinivas, G., Energy harvesting, reuse and upgrade to reduce primary energy usage in the USA. Energy 2011, 36, 6172-6183.

3. Loeb, S. Method and apparatus for generating power utilizing pressure-retarded osmosis. US Patent $3906250,1975$.

4. Logan, B. E.; Elimelech, M., Membrane-based processes for sustainable power generation using water. Nature 2012, 488, 313-319.

5. Carati, A.; Marino, M.; Brogioli, D., Thermodynamic study of a distiller-electrochemical cell system for energy production from low temperature heat sources. Energy 2015, 93, Part 1, 984-993.

6. Dean, J. A.; Lange, N. A.; Dean, J. A., Lange's Handbook of Chemistry. McGraw-Hill: 1992.

7. McGinnis, R. L.; McCutcheon, J. R.; Elimelech, M., A Novel Ammonia-Carbon Dioxide Osmotic Heat Engine for Power Generation. J. Membr. Sci. 2007, 305, 13-19.

8. Weinstein, J. N.; Leitz, F. B., Electric power from differences in salinity: the dyalitic battery. Science 1976, 191, 557-559.

9. Quickenden, T. I.; Mua, Y., A review of power generation in aqueous thermogalvanic cells. $J$. Electrochem. Soc. 1995, 142, (11), 3985-3994. 
10. Ponce de Leon, C.; Frias-Ferrer, A.; Gonzalez-Garcia, J.; Szanto, D. A.; Walsh, F. C., Redox flow cells for energy conversion. J. Power Sources 2006, 160, (1), 716-732.

11. Rica, R. A.; Ziano, R.; Salerno, D.; Mantegazza, F.; van Roij, R.; Brogioli, D., Capacitive mixing for harvesting the free energy of solutions at different concentrations. Entropy 2013, 15, (4), 1388-1407.

12. Peljo, P.; Lloyd, D.; Nguyet, D.; Majaneva, M.; Kontturi, K., Towards a thermally regenerative allcopper redox flow battery. Phys. Chem. Chem. Phys. 2014, 16, 2831-2835.

13. Zhang, F.; Liu, J.; Yang, W. L.; Logn, B. E., A thermally regenerative ammonia-based battery for efficient harvesting of low-grade thermal energy as electrical power. Energy Environ. Sci. 2015, 8, 343-349.

14. Kim, J. J.; Chung, J. S.; Kang, H.; Yu, Y. A.; Choi, W. J.; Kim, H. J.; Lee, J. C., Thermo-responsive copolymers with ionic group as novel draw solutes for forward osmosis processes. Macromol. Res. 2014, 22, (9), 963-970.

15. Zhu, X.; Rahimi, M.; Gorski, C. A.; Logn, B. E., A Thermally-Regenerative Ammonia-Based Flow Battery for Electrical Energy Recovery from Waste Heat. ChemSusChem 2016, 9, 873-879.

16. Marino, M.; Misuri, L.; Carati, A.; Brogioli, D., Proof-of-Concept of a Zinc-Silver Battery for the Extraction of Energy from a Concentration Difference. Energies 2014, 7, 3664-3683.

17. Flieger, J.; Czaijkowska-Zelazko, A., Ionic Liquids in separation techniques. In Applications of ionic liquids in science and technology, Handy, S., Ed. InTech: 2011.

18. Werner, S.; Haumann, M.; Wasserscheid, P., Ionic Liquids in Chemical Engineering. Annu. Rev. Chem. Biomol. Eng. 2010, 1, 203-230.

19. Cai, Y. F.; Shen, W. M.; Wei, J.; Chong, T. H.; Wang, R.; Krantz, W. B.; Fane, A. G.; Hu, X., Energy-efficient desalination by forward osmosis using responsive ionic liquid draw solutes. Environ. Sci.: Water Res. Technol. 2015, 1, 341-347.

20. Zhong, Y.; Feng, X.; Chen, W.; Wang, X.; Huang, K. W.; Gananou, Y.; Lai, Z. P., Using UCST ionic liquid as a draw solute in forward osmosis to treat high-salinity water. Environ. Sci. Technol. 2016, 50, 1039-1045.

21. Cai, Y. F.; Hu, X., A Critical review on draw solutes development for forward osmosis. Desalination 2016, 391, 16-29.

22. Straub, A. P.; Deshmukh, A.; Elimelech, M., Pressure-retarded osmosis for power generation from salinity gradients: is it viable? Energy Environ. Sci. 2016, 9, 31-48.

23. Yip, N. Y.; Elimelech, M., Comparison of energy efficiency and power density in pressure retarded osmosis and reverse electrodialysis. Environ. Sci. Technol. 2014, 48, 11002-11012.

24. Rebelo, L. P. N.; Najdanovic-Visak, V.; Visak, Z. P.; Nunes da Ponte, M.; Szydlowski, J.; Cerdeirina, C. A.; Troncoso, J.; Romani, L.; Esperanca, J. M. S. S.; Guedes, H. J. R.; de Sousa, H. C., A detailed thermodynamic analysis of $\left[\mathrm{C}_{4} \mathrm{mim}\right]\left[\mathrm{BF}_{4}\right]+$ water as a case study to model ionic liquid aqueous solutions. Green Chem. 2004, 6, 369-381.

25. Bendova, M.; Wagner, Z., Thermodynamic descriptionof liquid-liquid equilibria in systems 1-thyl-3methylimidazolium ethylsufate $+\mathrm{C} 7$-hydrocarbons by polymer-solution models. Fluid Phase Equilibria 2009, 284, 80-85.

26. Lei, Z. G.; Dai, C. N.; Liu, X.; Xiao, L.; Chen, B. H., Extension of the UNIFAC model for ionic liquids. Ind. Eng. Chem. Res. 2012, 51, 12135-12144.

27. Pitzer, K. S.; Peiper, J. C.; Busey, R. H., Thermodynamic properties of aqueous sodium chloride solutions. J. Phys. Chem. Ref. Data 1984, 13, (1), 3-102.

28. Lin, S. H.; Straub, A. P.; Elimelech, M., Thermodynamic limits of extractable energy by pressure retarded osmosis. Energy Environ. Sci. 2014, 7, 2706-2714.

29. Achilli, A.; Prante, J. L.; Hancock, N. T.; Maxwell, E. B.; Childress, A. E., Experimental Results from RO-PRO: A Next Generation System for Low-Energy Desalination. Environ. Sci. Technol. 2014, $48,(11), 6437-6443$.

30. Ramon, G. Z.; Feinberg, B. J.; Hoek, E. M. V., Membrane-based production of salinity-gradient power. Energy Environ. Sci. 2011, 4, (11), 4423-4434.

19 
407

408

409

410

411

412

413

414

415

416

417

418
31. Yip, N. Y.; Tiraferri, A.; Phillip, W. A.; Schiffman, J. D.; Hoover, L. A.; Kim, Y. C.; Elimelech, M., Thin-Film Composite Pressure Retarded Osmosis Membranes for Sustainable Power Generation from Salinity Gradients. Environ Sci Technol 2011, 45, (10), 4360-4369.

32. Straub, A. P.; Yip, N. Y.; Elimelech, M., Raising the Bar: Increased Hydraulic Pressure Allows Unprecedented High Power Densities in Pressure-Retarded Osmosis. Environ. Sci. Technol. Lett. 2014, 1 , (1), 55-59.

33. Han, G.; Zhang, S.; Li, X.; Chung, T.-S., High performance thin film composite pressure retarded osmosis (PRO) membranes for renewable salinity-gradient energy generation. J. Membr. Sci. 2013, 440, 108-121.

34. Gerstandt, K.; Peinemann, K. V.; Skilhagen, s. E.; Thorsen, T.; Holt, T., Membrane Processes in energy Supply for an Osmotic Power Plant. Desalination 2008, 224, 64-70. 
419 Table of Contents and Graphic Synopsis

420

421 